\title{
Garment knowledge base development based on fuzzy technology for recommendation system
}

DOI: 10.35530/IT.071.05.1724

\section{ABSTRACT - REZUMAT}

\section{Garment knowledge base development based on fuzzy technology for recommendation system}

With the rapid development of garments recommendation systems, more and more garment knowledge base have been widely developed. The research in this paper aims to build a garment knowledge base in order to help general consumers to identify the most relevant products satisfying their specific requirements. We design four experiments for building this knowledge base by 8 pairs of normalized sensory evaluation criteria for describing both consumers expectations and product profile. The theory of fuzzy composition technology is applied for setting up garment knowledge base which can be used for consumer-oriented intelligent garment recommendation system. Compared with the other knowledge base, this knowledge base is more robust and more interpretable owing to its capacity of handling vague, imprecise, uncertain, or ambiguous.

Keywords: fuzzy technology, sensory experiment, knowledge base

\section{Dezvoltarea bazei de cunoștințe despre articolele de îmbrăcăminte utilizând tehnologia fuzzy pentru sistemul de recomandare}

Odată cu dezvoltarea rapidă a sistemelor de recomandare a articolelor de îmbrăcăminte, au fost dezvoltate pe scară largă baze de cunoștințe din ce în ce mai extinse. Studiul din această lucrare își propune să construiască o bază de cunoștințe despre articolele de îmbrăcăminte, pentru a ajuta consumatorii să identifice cele mai relevante produse, care să îndeplinească cerințele lor specifice. Au fost proiectate patru experimente pentru construirea acestei baze de cunoștințe cu 8 perechi de criterii de evaluare senzorială, normalizate pentru a descrie atât așteptările consumatorilor, cât și profilul produsului. Teoria tehnologiei de compoziție fuzzy a fost aplicată pentru crearea bazei de cunoștințe despre articolele de îmbrăcăminte, care poate fi utilizată pentru sistemul inteligent de recomandare a articolelor de îmbrăcăminte orientate către consumator. Comparativ cu alte baze de cunoștințe, aceasta este mai robustă și mai interactivă datorită capacității sale de a gestiona informații vagi, imprecise, incerte sau ambigue.

Cuvinte-cheie: tehnologie fuzzy, experiment senzorial, bază de cunoștințe

\section{INTRODUCTION}

In the field of garment, knowledge can be divided into explicit knowledge and implicit knowledge based on the way of its acquisition. The explicit knowledge, referring to knowledge that can be explicitly expressed, can be acquired from oral instructions, textbooks, references, periodicals, patents, software and database and so on [1]. The explicit knowledge can be propagated through languages, books, text, database, and can be easily learned by human.

Implicit knowledge refers to tacit knowledge possessed by human experts in terms of skills and recognition, including not only skills and experiences that are informal and hard to express, but also insights, intuitions, inspirations, etc. Implicit knowledge exists in human brains, which dominate its various applications by human.

Knowledge originates from books, electronic data, expertise, and so on. The knowledge engineers can acquire knowledge from three sources:
- Indirect knowledge: experts provide their empirical and non-structured knowledge related to their past experiences by responding a well-organized questionnaire in some real scenarios.

- Direct knowledge: experts directly express their well-structured and formalized knowledge under the forms of generalized rules and relations.

- Knowledge from data: knowledge can be automatically and progressively learned from data.

This paper mainly deals with indirect knowledge and knowledge from data to set up the garment knowledge base. For an accurate and objective expression of knowledge on garments, it is important to analyse the characteristics of knowledge on garments, which can be summarized by a number of semantic statements.

Fuzziness: human's perception is fuzzy, and cannot be easily expressed. Thus, it is difficult to give quantitative results with traditional theories and methods when evaluating the perception on a garment. Also, the evaluation rules cannot be understood and stated 
with Boolean logic. The Kansei information expressed by a certain evaluation subject is not only uncertain but also multiple. Consequently, in practice, the Kansei information on garments can be expressed by utilizing fuzzy sets.

Complexity: garments are the most commonly-used consumer goods. However, its information is very complicated and rich. The complexity of a garment is not only embodied in its own structure and aesthetic perception, but also highlighted in the relationship between the garment and body shapes. For example, the same garment fitting with different consumer sizes, usually leads to a big difference in vision. This is so-called Kansei attraction of garments, which is difficult to understand.

Integrity: for garment products, design elements include a number of Kansei information, such as patterns, details, fabrics and so on. These elements are independent but interconnected between them, in order to show one specific identity. The perception on garments is related to the overall sensory effects on the combination of these elements. So, the evaluation on garments is performed with respect to overall perception [2].

The main computational tools used in this paper are fuzzy techniques which selected for modelling and analysis of professional knowledge and human perceptions at different levels by taking into account the previous characteristics.

\section{FUZZY TECHNOLOGY}

The entire real world is complex and the complexity arises from vagueness. If the complexity of a problem exceeds a certain threshold, the system must become vague in nature. And with the increase of complexity, our ability of making precise judgments about the behaviuor of the system diminishes [3]. There is a rapid decline in the information afforded by traditional mathematical models due to their insistence on precision.

Compared with traditional system modelling and analysis techniques, fuzzy sets have the following strengths:

- It is conceptually easy to understand. The mathematical concepts behind fuzzy reasoning are simple.

- It is tolerant with vague data. Most of things are imprecise even on careful inspection. Fuzzy reasoning permits to build this understanding into the process rather than tacking it onto the end.

- It is based on natural language. The basis for fuzzy logic is the basis for human communication.

Natural language is the carrier of efficient communication. Since fuzzy logic is built atop the structures of qualitative description used in everyday language, it is easy to use.

Some major areas of fuzzy applications in textile/garment industry include classifications, recommendations, decision-making and so on, related to materials, finished products, consumers, markets and manufacturing processes. An example is body size classification using the fuzzy c-means clustering algorithm. Also, a method of fuzzy comprehensive evaluation has been investigated for fabric stiffness handle [4]. And an intelligent system based on fuzzy logic has been developed for optimization of the textile and garment supply chain [5]. Moreover, an intelligent system based on the fuzzy techniques has been developed to evaluate fabric shape style based on motion capture [6].

In this paper, we develop a garment knowledge base by fuzzy composition technology. This knowledge base is about women's jeans, and is widely use in garment recommendation system for special consumers.

First, we design four experiments to build the knowledge base, Experiment 1,2 and 3 are designed to find out the relation between consumer profile (body shapes, style keywords, visual images) and a set of predefined normalized evaluation criteria. Experiment 4 finds out the relations between the product profile (garment fitting and details) and the same normalized evaluation criteria.

Second, knowledge base 1 (KB1) is set up from the data get in Experiment 1, 2 and 3, while knowledge base 2 (KB2) is established from the data get in Experiment 4.

Finally, KB1 and KB2 form the knowledge base through fuzzy composition operation. The process of building the knowledge base is shown in figure 1.

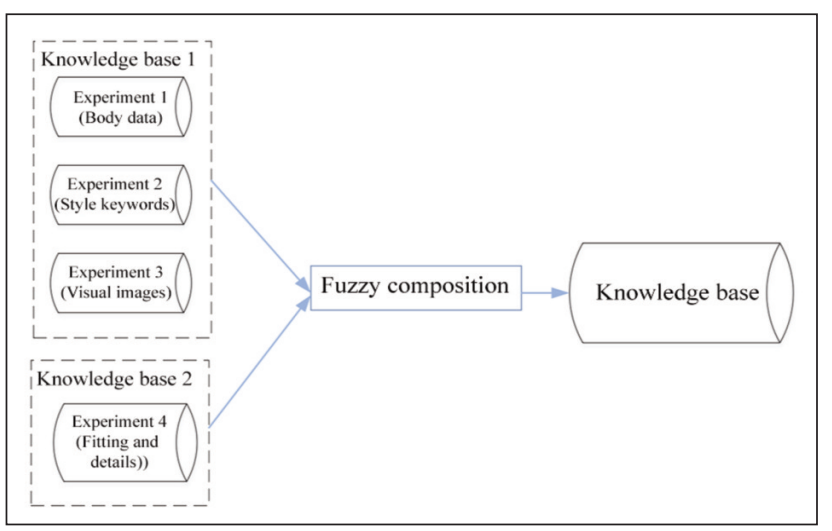

Fig. 1. The process of building the knowledge base

\section{Fuzzy theory}

Words like "young", "tall", "good", and "high" are fuzzy. There is no single quantitative value for characterizing the term "young". For some people, age 20 is young, and for others, age 30 is young. The concept young have no clear boundary.

In the real world, there exists a lot of human knowledge. By nature, knowledge is vague, imprecise, uncertain, ambiguous, or probabilistic. Human thinking and reasoning frequently involve fuzzy information, originating from vague human concepts. Humans can give satisfactory answers, which are probably true.

However, most of automatic systems are designed based upon classical set theory and two-valued logic 
which is unable to cope with unreliable and incomplete information and give expert opinions. In this situation, fuzzy technology has shown their special advantages of dealing with both human knowledge and uncertain information.

\section{Fuzzy composition relation}

Let $R$ be a fuzzy relation defined on a Cartesian space $X \times Y, S-$ a fuzzy relation on $Y \times Z$, and $T-a$ fuzzy relation on $X \times Z$. The most used composition method for linking two fuzzy relations is called maxmin composition:

$$
\begin{aligned}
T= & R \circ S \\
= & \left\{(x, z), \max \left\{\min \left(\mu_{R}(x, y), \mu_{S}(x, y)\right)\right\} \mid x \in X,\right. \\
& y \in Y, z \in Z\}
\end{aligned}
$$

\section{EXPERIMENTS PROCEDURE}

A consumer profile is a way of describing a consumer which can be defined in different ways. In this paper, we define the consumer profile as the combination of three parts, such as body shape, style keywords and visual images.

Product profile describes jeans, we define the product profiles as two parts, such as garment fitting levels and garment details.

\section{Experiment 1}

Experiment 1 aims to extract the fashion knowledge and experience from fashion designers about the relations between body shapes and evaluation criteria. The components and the procedures of experiment 1 are given below.

Body data

Since the purpose of this paper is to set up the garment knowledge base of Chinese women whose ages are from 18 to 25, we select four basic body measurements: b1: Stature, b2: Chest Circumference, b3: Waist Circumference, b4: Weight [7].

The Chinese Standard Human Body Database (female) is available in our study. It is covering the body types of the whole Chinese female population. The statures of these samples are arranged from 145 $\mathrm{cm}$ to $175 \mathrm{~cm}$ with a step length of $5 \mathrm{~cm}$. According to this database, four standard body types $(Y, A, B, C)$ are defined from the difference of chest circumference and waist circumference.

- Y means that Chest Circumference minus Waist Circumference is between $19 \mathrm{~cm}$ and $24 \mathrm{~cm}$.

- A means that Chest Circumference minus Waist Circumference is between $14 \mathrm{~cm}$ and $18 \mathrm{~cm}$.

- B means that Chest Circumference minus Waist Circumference is between $9 \mathrm{~cm}$ and $13 \mathrm{~cm}$.
- C means that Chest Circumference minus Waist Circumference is between $4 \mathrm{~cm}$ and $8 \mathrm{~cm}$.

In practice, these fours body types cover more than $99 \%$ of the whole population of Chinese women (table 1).

We use the Clo3D software to build a 3D virtual body with a standard neutral face expression shapes. In this paper, evaluation of human body shapes with 3D human models created by Clo3D for a specific consumer is more efficient than that with real body shapes [8]. In fact, some real body shapes, especially special shapes like sportsmen, are not always available in classical evaluation sessions.

Consumers should input four body data by manually taking measures on b1 (Stature), b2 (Chest Circumference), b3 (Waist Circumference) and b4 (Weight). After inputting these body data, the 3D human model of the specific consumer can be built by Clo3D.

We can describe the level of tall-low as five levels: X1: short, X2: a little short, X3: middle, X4: a little tall, X5: tall. We can name fat-thin as four levels: $Y 1$ : underweight Y2: normal, Y3: overweight, Y4: obese. Therefore, the entire body shapes can be described by 20 combinations. Which is " $\mathrm{X} 1 \times Y 1$ ", "X2×Y1", "X3×Y1", "X4×Y1", "X5×Y1", "X1×Y2”, "X2×Y2", "X3×Y2", "X4×Y2", "X5×Y2", "X1×Y3", "X2×Y3", "X3×Y3", "X4×Y3", "X5×Y3", "X1×Y4", "X2×Y4", "X3×Y4", "X4×Y4", "X5×Y4". For any specific body shape, we require each evaluator to give a predefined five levels of score for each of the eight evaluation criteria. We can use a $(20 \times 8)$-dimensional matrix to express the evaluation data. The 20 body shapes correspond to the following images (table 2).

In experiment 1, 42 undergraduate and graduate students and 3 textile industry experts are invited to act sensory evaluators. Finally, for each evaluator, the evaluation scores for the 8 sensory descriptors and all 20 virtual body shapes compose a $(20 \times 8)$-dimensional matrix.

\section{Experiment 2}

Experiment 2 aims to extract from human perception, fashion designer's knowledge about the relations between style keywords and evaluation criteria. There are many words used to describe garments styles such as: Fashion, Elegant, Feminine, Young, Sexy, Classic, Romantic, and Sporty.

The process of selecting the style keywords is presented below. First, 20 various style keywords describing garments are summarized from the Internet and fashion trends magazine. Then each fashion expert evaluates the relevancy of each style keyword to female jeans by giving an evaluation

\begin{tabular}{|c|c|c|c|c|}
\hline \multicolumn{5}{|c|}{ FOUR BODY TYPES OF CHINESE STANDARD HUMAN BODY DATABASE } \\
\hline Parameters & $\mathbf{Y}$ & $\mathbf{A}$ & $\mathbf{B}$ & $\mathbf{C}$ \\
\hline b2-b3 & $19 \mathrm{~cm}-24 \mathrm{~cm}$ & $14 \mathrm{~cm}-18 \mathrm{~cm}$ & $9 \mathrm{~cm}-13 \mathrm{~cm}$ & $4 \mathrm{~cm}-8 \mathrm{~cm}$ \\
\hline proportion & $14.82 \%$ & $44.13 \%$ & $33.72 \%$ & $6.45 \%$ \\
\hline
\end{tabular}




\begin{tabular}{|c|c|c|c|c|}
\hline \multicolumn{5}{|c|}{ THE 20 BODY SHAPES USED IN EXPERIMENT 1 } \\
\hline $\mathrm{X} 1 \times \mathrm{Y} 1$ & $\mathrm{X} 2 \times \mathrm{Y} 1$ & $\mathrm{X} 3 \times \mathrm{Y} 1$ & $\mathrm{X} 4 \times \mathrm{Y} 1$ & $\mathrm{X} 5 \times \mathrm{Y} 1$ \\
\hline & $\mathrm{X}$ & & \\
\hline
\end{tabular}

score from 1 to 10 with the help of corresponding explanation and image. The final 8 style keywords are determined by choosing the keywords corresponding to the 8 highest averaged evaluation scores.

After identifying the 8 style keywords describing women's garments, we invite the same fashion experts to evaluate the relations between the 8 style keywords and the 8 normalized sensory evaluation criteria. For each expert, all the evaluation scores are collected in a (8×8)-dimensional matrix.

The experiment 2 is not only limited to these 8 style keywords. If a new style keyword is added (for example "wild"), we can update the evaluation matrix by either introducing new evaluation scores on this new keyword or expressing it using the combination of the existing keywords.

In experiment 2, 50 undergraduate and graduate students and 10 university professors are invited to play the role of sensory evaluators. The used 8 sensory descriptors are the same as in Experiment 1. The evaluation results of each evaluator compose a (8×8)-dimensional matrix.

\section{Experiment 3}

Experiment 3 can identify the relations between visual images (ambiances) and evaluation criteria. During the purchasing event, consumers do not completely know which garment is really suitable for them but they just master some vague verbal expressions that describe their expectations. In experiment 3, we perform a series of evaluations so that the selected consumers of the target population choose the most relevant images according to their requirements.

Six images have been chosen in experiment 3. For each Visual image, a number of representative photographs, are presented in order to make the evaluators understand it more easily.

Each consumer is asked to select a pair of favourite jeans from the following pictures based on her consumer preference. For each evaluator, her evaluation data are collected on a $(6 \times 8)$-dimensional matrix. The updating of this evaluation matrix follows the same principle as that of style keywords. 
In fact, evaluations with image are complementary to evaluation with style keywords. In this paper, the body data, the style keywords and visual images constitute together the consumer profile.

50 undergraduate and graduate students and 10 university professors are invited to participate in experiment 3. These consumer evaluators fill out the questionnaire separately. Finally, the results obtained from each consumer evaluator compose a $(6 \times 8)$-dimensional linguistic matrix.

\section{Experiment 4}

Experiment 4 aims to extract from the perceptions, fashion designer's knowledge about the relations between design style and evaluation criteria.

The most important part of the garment is two parts: fitting of a garment style and details. Five values of fitting of a garment styles are assumed in experiment 4. For each fitting of a garment style, a number of representative photographs are presented to make it more easily for the evaluators to understand it.

We have three parts of details: the details of waist, the details of leg opening and the details of ornamental. For each fitting of a garment style, a number of representative photographs are presented in order to make the evaluators understand it more easily.

The recombination of the general fitting ( 5 evaluation levels) and the three parts of details $(3+3+2$ evaluation levels) can determine a product profile (13 evaluation levels covering all the cases). When evaluating the relations between design styles and evaluation criteria, each expert gives scores to the fitting effect and each detail with the 8 evaluation criteria.

For all the 13 evaluation levels describing a product, their relations with the 8 evaluation criteria constitute a $(13 \times 8)$-dimensional matrix for each evaluator.

In experiment 4, 10 textile industry experts are invited to play the role of sensory evaluators. The evaluation results of each evaluator compose a $(13 \times 8)$ dimensional matrix.

\section{MATHEMATICAL FORMALIZATION}

After obtaining human perceptual data from the trainees participating in the 4 experiments, we give the mathematical formalization of the related concepts. Finally, the garment knowledge base can be set up by fuzzy composition relations.

1: Let $E=\left\{e_{1}, e_{2}, \ldots, e_{p}\right\}$ be a set of $p$ evaluation criteria.

2: Let $B S=\left\{b s_{1}, \ldots, b s_{m}\right\}$ be a set of $m$ body shapes $(m=20)$.

3: Let $S=\left\{s_{1}, \ldots, s_{n}\right\}$ be a set of $n$ style keywords $(n=8)$.

4: Let $C=\left\{c_{1}, \ldots, c_{k}\right\}$ be a set of $k$ visual images $(k=6)$.

Let $N$ be the total number of consumer profile. We have $N=m+n+k$.

5: Let $G=\left\{g_{1}, \ldots, g_{h}\right\}$ be a set of $h$ fitting levels $(h=5)$.

6: Let $D W=\left\{d w_{1}, \ldots, d w_{x}\right\}$ be a set of $x$ details of waist $(x=3)$.

7: Let $D F=\left\{d f_{1}, \ldots, d f_{y}\right\}$ be a set of $y$ details of leg opening $(y=3)$.
8: Let $D O=\left\{d o_{1}, \ldots, d o_{z}\right\}$ be a set of $z$ details of ornamentals $(z=2)$.

The $M$ variables describing product profile with $M=h+x+y+z$.

9: Let $K B_{B S}$ be the knowledge base get from the Experiments 1 , describing the relations between $B S$ and $E$. It is expressed by a $(m \times p)$-dimensional matrix.

10: Let $K B_{S}$ be the knowledge base get from the Experiments 2, describing the relations between $S$ and $E$. It is expressed by a $(n \times p)$-dimensional matrix.

11: Let $K B_{C}$ be the knowledge base get from the Experiments 3, describing the relations between $C$ and $E$. It is expressed by a $(k \times p)$-dimensional matrix.

12: Let $K B_{G}$ be the knowledge base get from the Experiments 4, describing the relations between $E$ and $G$. It is expressed by a $(p \times h)$-dimensional matrix.

13: Let $K B_{D W}$ be the knowledge base get from the Experiments 4, describing the relations between $E$ and $D W$. It is expressed by a $(p \times x)$-dimensional matrix.

14: Let $K B_{D F}$ be the knowledge base get from the Experiments 4, describing the relations between $E$ and $D F$. It is expressed by a $(p \times y)$-dimensional matrix.

15: Let $K B_{D O}$ be the knowledge base get from the Experiments 4, describing the relations between $E$ and $D O$. It is expressed by a $(p \times z)$-dimensional matrix.

16: Let $K B_{1}$ be the knowledge base get from the Experiments 1, 2, 3, describing the relations between the $N$ consumer profiles and $E$.

17: Let $K B_{2}$ be the knowledge base get from the Experiments 4 describing the relations between $E$ and the $M$ product profiles.

\section{Computing knowledge base}

From the matrices $K B_{B S}, K B_{S}$ and $K B_{C}$, we get the matrix $K B_{1}=\left|\begin{array}{l}K B_{B S} \\ K B_{S} \\ K B_{C}\end{array}\right|$. From the matrices of $K B_{G}$, $K B_{D W}, K B_{D F}$ and $K B_{D O}$, we get the matrix $K B_{2}=\left[K B_{G}\right.$ $K B_{D W} K B_{D F} K B_{D O}$. By successive combinations the $K B_{1}$ and $K B_{2}$, we get knowledge base of the consumer profile and product profile by fuzzy composition technology, named as $K B$.

$K B=K B_{1} \circ K B_{2}$.

\section{CONCLUSION}

The garment knowledge base about consumer profile and product profile of the women's jeans was built by applying the principle of fuzzy composition technology. This garment knowledge base can be used on a garment recommendation system for special consumers [8]. Fuzzy techniques are the main computational tool used in this paper because they are more relevant to modelling and analysis of the acquired 
data. In fact, the evaluation data on body shapes, style keywords and visual images can never be accurately expressed.

The research method of this paper can be directive for other researches on the knowledge between any kind of garments or fashion products. In addition, the method of building the garment knowledge base can be widely used for consumer-oriented recommendation system. It can guide shoppers and manufactures to recommend more competitive garments or fashion products in the consumer-oriented market. Compared with the other knowledge base, this knowledge base is more robust and more interpretable owing to its capacity of handling vague, imprecise, uncertain, or ambiguous.

Due to limited time, only the female jeans knowledge base was built in this paper. Further research could be arranged to apply fuzzy technology on other fashion fields such as suit, shoes, accessories and more.

\title{
REFERENCES
}

[1] Wenger, E., Artificial intelligence and tutoring systems: computational and cognitive approaches to the communication of knowledge, Morgan Kaufmann, 2014

[2] Zhang, J., et al., Jeans knowledge base development based on sensory evaluation technology for customers' personalized recommendation, In: International Journal of Clothing Science \& Technology, 2018, 30, 1, 101-111

[3] Lazarus, S.A., et al., Interpersonal functioning in borderline personality disorder: A systematic review of behavioral and laboratory-based assessments, In: Clinical psychology review, 2014, 34, 3, 193-205

[4] Sun, F., et al., Fuzzy comprehensive prediction of fabric stiffness handle based on quasi-three-point restraint test, In: Fibers and Polymers, 2015, 16, 6, 1395-1402

[5] Ngai, E., et al., Decision support and intelligent systems in the textile and apparel supply chain: An academic review of research articles, In: Expert Systems with Applications, 2014, 41, 1, 81-91

[6] Li, Y., et al., A new method to evaluate fabric shape style based on motion capture, In: Fibers and Polymers, 2015 , $16,1,201-208$

[7] Zhang, J., et al., Consumer-Oriented Intelligent Garment Recommendation System, In: Uncertainty Modelling in Knowledge Engineering and Decision Making: Proceedings of the 12th International FLINS Conference, World Scientific, 2016

[8] Zhang, J., et al., Recommending Garment Products in E-Shopping Environment by Exploiting an Evolutionary Knowledge Base, In: International Journal of Computational Intelligence Systems, 2018, 11, 1, 340-354

\section{Authors:}

\section{JUNJIE ZHANG ${ }^{1}$, XIANYI ZENG ${ }^{2}$, MIN DONG $^{1}$, WEIBO LI ${ }^{3}$, HUA YUAN $^{4}$}

${ }^{1}$ Hubei Key Laboratory of Digital Textile Equipment, Engineering Research Center of Hubei Province for Clothing Information, School of Mathematics and Computer Science, Wuhan Textile University, 430073 Wuhan, China

${ }^{2}$ Laboratoire Génie et Matériaux Textile (GEMTEX), France

${ }^{3}$ Wuhan Textile University, School of economics, 430073, Wuhan, China

${ }^{4}$ Wuhan Textile and Apparel Digital Engineering Technology Research Center, School of fashion, Wuhan Textile University, 430073, Wuhan, China

\author{
Corresponding authors: \\ WEIBO LI \\ e-mail: 2862852361@qq.com \\ HUA YUAN \\ e-mail: 2019009@wtu.edu.cn
}

